\title{
Optimizing Farmer Business Case for Cocoa Agroforestry Systems Through Resilient Productivity
}

ISSN: 2637-7659

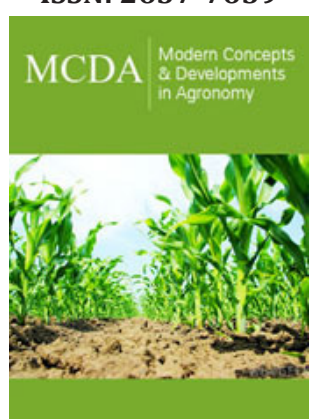

*Corresponding author: Bisseleua D Hervé Bertin, World Cocoa Foundation, Accra, Ghana

Submission: 笽 November 11, 2019

Published: 非 November 20, 2019

Volume 5 - Issue 3

How to cite this article: Bisseleua D Hervé Bertin. Optimizing Farmer Business Case for Cocoa Agroforestry Systems Through Resilient Productivity. Mod Concep Dev Agrono.5(3). MCDA.000613.2019.

DOI: 10.31031/MCDA.2019.05.000613

Copyright@ Bisseleua D Hervé Bertin, This article is distributed under the terms of the Creative Commons Attribution 4.0 International License, which permits unrestricted use and redistribution provided that the original author and source are credited.

\author{
Bisseleua D Hervé Bertin* \\ World Cocoa Foundation, Ghana
}

\begin{abstract}
In West Africa agriculture including cocoa farming is by far the largest employer of people as most of the food produced comes from the farms and fields of smallholders. However, the continent suffers shortages of food mainly arising from low production, lack of proper storage and a weak supply chain, and economic systems in fundamental ways. This is especially the case in the face of climate change, deforestation and land degradation that threaten cocoa farming, agriculture in general and the regulation and provision of critical ecosystem services. This way of working includes many features from the Green Revolution of the 1960s. First launched in Mexico and the Indian sub-continent, these techniques later expanded to Africa. We therefore need a big rethink of the traditional approaches to cocoa production. This needs to consider the health of the planet and the fact that Green Revolution farming techniques are simply too complex and costly for many small farmers. In addition, cocoa farmers need to diversify into other crops. There is a need to adapt the Green Revolution to the local conditions of cocoa famers and consider ecological, social, and economic conditions. We here present a new concept and methods to revive the cocoa sector called resilient productivity that covers agroforestry and ago-ecological intensification, diversity of species, lifeforms, livelihoods, value chains, and systems. The concept implies a genuine option by context model of responsible cocoa production based on implications for overall food production, livelihoods, resilience, and development.
\end{abstract}

Keywords: Cocoa agroforestry system, Biodiversity conservation, Food production, Resilient productivity, Livelihoods, Sustainable development

\section{Introduction}

Chocolate is one of the most universal treats in the world. But could your sweet tooth actually be accelerating biodiversity loss? The chocolate tree, cocoa (Theobroma cacao) is traditionally grown in areas with dense and diverse canopies of shade trees, home to an abundant variety of plants and animals [1-5]. The industry is strongly dependent on smallscale agriculture, but also highly vulnerable to pest and disease outbreaks, and climate change $[6,7]$. These production challenges combined with increasing global demand for chocolate has increased the economic and social pressure to achieve higher yields within a shorter timeframe. The path to higher yields involves a combination of better practices, an enabling environment of favourable policies and regulations, and a health natural environment. Historically, higher yields have been achieved through a constant expansion of areas planted with cocoa combined with a reduction of shade trees and the increased use of chemical pesticides and fertiliser [7-9].

A system that is often referred to as full sun cocoa production. But these techniques lead to deforestation, biodiversity loss, and poor ecosystem functioning. Higher yields in the short term is also not sustainable over a long time: work in Côte D'Ivoire, Ghana, Cameroon and elsewhere showed that the promotion of high-yielding hybrid cocoa varieties under direct full sun have contributed to more frequent outbreaks of pests and diseases $[2,10]$. 
Recent predictions indicate that higher future temperatures will make some areas currently under cocoa no longer suitable, but shade management could be used to buffer this. Agroforestry (AF), referring here to planting or managing the regeneration of companion trees with cocoa, can make important contributions to enhancing and sustaining cocoa productivity because it can provide the following benefits:

A. refugia for biodiversity and other attendant ecosystem services

B. reduce agronomic and economic risks associated with monoculture cocoa, including control of some pests and diseases

C. Provide farmers with nutritious and healthy tree foods

D. Diversify income sources for farmers through the addition of forest fruits and timber products

E. increase nutrient and water use efficiency of cocoa production

F. provide for community timber and firewood needs

G. improve the agro-ecological balance in the landscape, and

H. reduce deforestation and forest degradation.

Achieving these benefits requires appropriate management of both the companion trees and the cocoa orchards [5,11]. A dynamic cocoa growing management system that uses various combinations of other plant species, including food crops, food trees (fruits, nuts, tree-vegetables and oils), and medicinal plant as well as timber trees in association with cocoa currently holds some emerging potential benefits for smallholder farmers $[12,13]$. Such options are likely to create positive synergies with sustainable livelihoods that empower farmer communities and lead to prosperous farmers and a healthy planet. In Côte d'Ivoire, many initiatives exist to promote cocoa based agroforestry systems [3]. For instance, the 10-yr strategy elaborated by le Conseil Café-Cacao, 2QC (Quality, Quantity and Growth) aims to improve farming practices, enhance soil and disease management, and rejuvenate cocoa tree and farms. Diversification at the landscape level is one of the priorities for 2QC. The strategy calls for agroforestry techniques to sustainably maintain and improve cocoa productivity. Public institutions as well as national universities and farmers communities do have a vital role to play. Other public institutions dealing with environment, forest and conservation issues are also active in the search for a sustainable approach to preserve productive ecosystems. Since the launch of the Cocoa and Forests Initiative, nearly two years ago, the issue of deforestation is attracting a lot of interest from the private sector because it is a concern for the long-term viability of the worldwide cocoa supply and a growing concern amongst chocolate consumers.

Thus, the development of sustainable production systems with a landscape approach is a priority for the public-private partnership platform of the cocoa sector. Besides, certification agencies, multilateral donors and international organizations are keen to invest in the preservation of ecosystem services and the development of sustainable production systems. A multistakeholder approach is necessary to optimize the farmer business case for cocoa agroforestry systems and looking at practical tools and financial opportunities to implement cocoa agroforestry models in Côte d'Ivoire and the West African cocoa belt while tackling ecological sustainability as well as the social and economic challenges of the cocoa sector. As an industry body but also one with strong roots into farmer communities, we find ourselves asking some fundamental questions:

A. How can you optimize the farmer business case for cocoa agroforestry without sacrificing income or environmental benefits?

B. How to enhance the ecological and economic benefits of cocoa agroforestry for the entire production landscape?

C. What skills, technologies, and incentives are necessary to effectively and efficiently implement cocoa agroforestry systems in West Africa?

D. How to sustain the production-protection agreement between stakeholders in the value chain through cocoa agroforestry systems?

\section{Are cocoa agroforestry systems ecologically and economically beneficial to farmers?}

During recent decades we have seen a transformation of cocoa farming to more intensified systems by eliminating shade trees, increasing agro-chemical inputs and selecting genotypesall to increase short-term income [4,7]. This has resulted in a broad range of cocoa plantation management, ranging from low input shaded plantations to high-input full sun plantations, some of which begin to approximate a monoculture production system $[2,5]$. Agroforestry is yet to receive key attention by the agricultural policy. Until very recently, most West African governments have since independence encouraged smallholder farmers to clear forest to establish plantations.

Policies and agronomic practices towards higher yielding varieties and full sun cocoa have contributed to further deforestation. In the colonial forest policy law, trees belonged to the government. It is assumed that shaded plantations are less profitable, but this assumption is often based on incomplete cost-benefit calculations. This is because cocoa productivity is often used as a proxy for profitability, which is assumed to be lower for shaded systems. Moreover, the costs associated with producing cocoa are usually not considered (Clough 2009). Additionally, the direct (economic) and indirect (Ecological) benefits derived from shade trees and food crops associated to cocoa such as banana and plantains are often not included in the calculations [14]. Although the business case for conventional plantations can be more straightforward, the calculation of the costs and benefits for shaded plantations is more complex because it includes all costs and benefits in a more comprehensive and realistic way. In such calculation, one could consider the premium price paid to farmer per kilogram of cocoa produced from shaded systems. The price of shade-produced cocoa or the price premiums from environmental certification 
schemes with Fairtrade, Rainforest are potentially higher due to increased quality and therefore suitable for specialty markets [15]. In certification scheme, the price received per kilogram of dry cocoa beans is always higher $(+18 \%)$ for farmers growing shaded cocoa compared to the price received for conventionally grown cocoa. Price premiums received by small-scale farmers as a result of environmental certification thus seem to play an important role and show potentially better economic prospects for small-scale farming, as the specialty cocoa market has increased over the last decade and is expected to keep growing [16]. Maybe we should be thinking to commit to 100 percent certified cocoa and create the enabling environment for that to happen.

If farmers are to consider switching from a conventional to a shaded system, the presumed decrease in cocoa yield needs to be compensated by a price premium, irrespective of the difference in quality of the product. Therefore, it will be important for farmers to be knowledgeable about the code of conduct of the exiting certification scheme. An aggregated certification scheme with codes and practices based on the consolidation of all the codes and practices demanded by the existing certifications (Rainforest, Fairtrade, etc.) could reduce multiple certifications by farmers. We could think of building a collective learning platform that will train farmers, youth, and community-based organizations to use the aggregated certification scheme. This could mean developing an integrated decision-making tool kits for cocoa production under agroforestry. The good news is that West Africa's cocoa farmers are now gradually moving back to agroforestry practices that embrace increased shade tree diversity with the aim to achieve more sustainable cocoa production, and to benefit from ecosystem services such as enhanced biological control of pests and diseases, and increased soil fertility. Farmers adopting these techniques are already reaping benefits. Complex agroforestry systems can sustain species richness equivalent to more than $60 \%$ of that of natural forests $[1,17]$.

For instance, in Ghana and Cameroon, cocoa yields from shaded cocoa agroforestry systems are $12-23 \%$ higher compared to full sun systems. In eastern Côte d'Ivoire, the use of leguminous trees as shade in rehabilitated cocoa plantations is also reported to increase the survival rate and yield of cocoa trees $[13,5]$. Cocoa grown in shade may produce for 60-100 years, whereas production may only last for 20 years without shade [18]. In addition to environmental services, diversified shade trees provide additional income opportunities such as timber and firewood production, medicine, local spices, and fruit, from native shade trees such as the ackui/njangsang tree (Ricinodendron heudelotii) and bush mango (Irvingia gabonensis) $[3,19]$. Importantly, in all these multilayer systems, a diversified shade trees meant more and diversified pollinators and biological pest control agents such as ants and social wasps, which in turn increased cocoa yields and revenue $[7,20]$. So far we see no consensus on how productive and profitable existing cocoa agroforestry systems are in comparison to intensive, conventional management systems [10]. Some researchers state that agroforestry, representing a form of extensive land use, cannot meet the growing demand for food; therefore, they advocate agricultural intensification to minimize the conversion of natural habitats [21]. Others, however, suggest that cocoa systems can be designed to optimize both biodiversity and economic benefits without adding pressure on natural habitats $[7,10]$. They based their argument on the fact that shaded cocoa systems are known to correlate positively with biodiversity and will offer competitive business opportunities for small-scale farmers while also contributing to biodiversity conservation.

They recommend strengthening the economic and biodiversity benefits of shaded cocoa systems, as well as informing small-scale farmers on opportunities and strategies to reconcile these two benefits. As smallholder farmers are at the heart of this transition, I recommend that incentives and enabling frameworks should focus on improving good agricultural practices (GAP). Agroforestry in combination with GAP would play a key role in addressing the critical situation of West African forests while ensuring the future of cocoa production and to make sure investments are consistent with national policies and are harmonized with socioeconomic and environmental objectives of prosperous farmers, empowered communities in a healthy planet.

\section{Skills, technologies and incentives for sustainable cocoa production}

Cocoa was introduced in Africa by Portuguese in the Fernando Do Po island known today as Equatorial Guinea and Sao Thomé et Principe. The production was later introduced to Cameroon by the German in the mid-1800. In these countries' cocoa was grown under a high diversity of multistate of forest and non-forest tree species from which products and goods are harvested such as timber, fodder, fuelwoods, medicine and food including insects. When Tetteh Quarshie introduced cocoa in Ghana in 1870, the country decided to mimic the same type of system as in Central Africa. But when cocoa was introduced to Côte d'Ivoire in the mid 1900 the country decided to go full sun with the aim to maximize yield using improved varieties that was called hybrids-this was based on recommendations by scientists that hybrids are not shade tolerant and that yield is low with shade. This new way of growing cocoa quickly spread from Cote d'Ivoire to Ghana and later to Central Africa including Cameroon.

However, part of Ghana and Cameroon decided to continue growing cocoa in a "traditional" way by keeping a diversity of shade/ companion trees in their farms and by gradually replacing the local cocoa varieties known in Ghana as "Tetteh Quashie cocoa" and in Cameroon as "German cocoa" with the hybrid varieties. A system which is known today as cocoa agroforestry system. For these two countries, we have scientific data showing how the presence of noncocoa trees on farms affects cocoa yields and the income. These data provide a better understanding of the profitability of cocoa production in agroforestry systems, making it possible to build robust business cases. If we want to understand how to establish a good cocoa agroforestry system, how much it will cost and what type of benefit can be derived, we have to go back to the countries of birth of this system which are in Central Africa. 


\section{So, what have we learned from Cameroon and Ghana?}

Cocoa is an understorey tree, growing in the shade of considerably larger trees. In Cameroon and Ghana, the shade comes mostly from native forest trees, thinned out to provide space for cocoa seedlings to be planted, or, to a lesser extent, from trees specially planted to provide shade $[2,13,22]$. Banana and/ or plantain is commonly used to provide temporal shade to young cocoa trees and as the trees mature, the native trees that are retained and the new, exotic trees planted, provide not just shade, but can also be used to provide extra income. This mixture of shade trees and shrubs creates a three-layer canopy, one level below the cocoa trees and two levels above them. The result is a multi-species system similar in structure and function to a forest-an agroforest system. About $80 \%$ of the cocoa plantation in Cameroon and Ghana is grown with some level of shade. They are grouped into six general types of cocoa agroforestry system, including full sun cacao, cocoa under heavy diversified shade, moderate and intermediate shade $[5,7]$.

Cocoa agroforestry systems of Cameroon are designed to improve household nutrition and farm income, food and income security, and offer a higher return on inputs and labour. The system is also designed to further enhance biodiversity, carbon sequestration, soil fertility, and pest and disease control [2,11,23,24]. Diversification with food crops (e.g. bananas/plantains, cassava, maize, beans, vegetables, etc.), fruit trees and agroforestry tree species are providing financial means and income during the unproductive phase of 3 to 4 years. These systems are designed to meet the responsible production concept and structurally resemble natural forests to some degree. They provide important habitats for several animal and plant species which ensure some key processes in the ecosystem like crop pollination, soil fertilization and pest and disease regulations.

They require marginal external inputs and can be grouped into four model

a. cocoa associated with forest and fruit trees;

b. cocoa associated with food crops (cassava, Maize, groundnuts and or cocoyam);

c. cocoa associated with plantains and agroforestry tree species; and

d. cocoa associated with oil palm and plantain/bananas (Bisseleua et al. 2018).

Management techniques include frequent weeding, pruning and mulching, as well as keeping organic materials that accumulates at harvest such as cocoa husks and banana stems in the plantations where they can decompose $[16,25,26]$. Yield averages between $800-2300 \mathrm{~kg} / \mathrm{ha}$ of marketable dry beans. Furthermore, each farm can provide about $8.7 \mathrm{~m} 3$ of commercial volume timber; $6-8,000 \mathrm{~kg} / \mathrm{ha}$ of bananas and plantains, 4-5,000l/ha of oil palm, between $140-220 \mathrm{~kg} / \mathrm{ha}$ of fruits and $10-18 \mathrm{~kg} / \mathrm{ha}$ of non-forest products harvested every year and generate a net annual profit between US $\$ 5,000$ to 13,000 to farmers (Figure 1). This suggest that cocoa agroforestry in Cameroon is profitable. A recent study from Djuideu et al. [5] found that intermediate cocoa agroforestry system with moderate shade is the most profitable. A study of 200 cocoa farmers from the Western region of Ghana found that medium-shade agroforestry was more profitable than no-shade, low-shade, and heavy-shade systems [13]. These findings suggest that promoting medium-shade cocoa agroforestry would be the right policy to ensure the welfare of cocoa farmers and enhancing environmental sustainability.

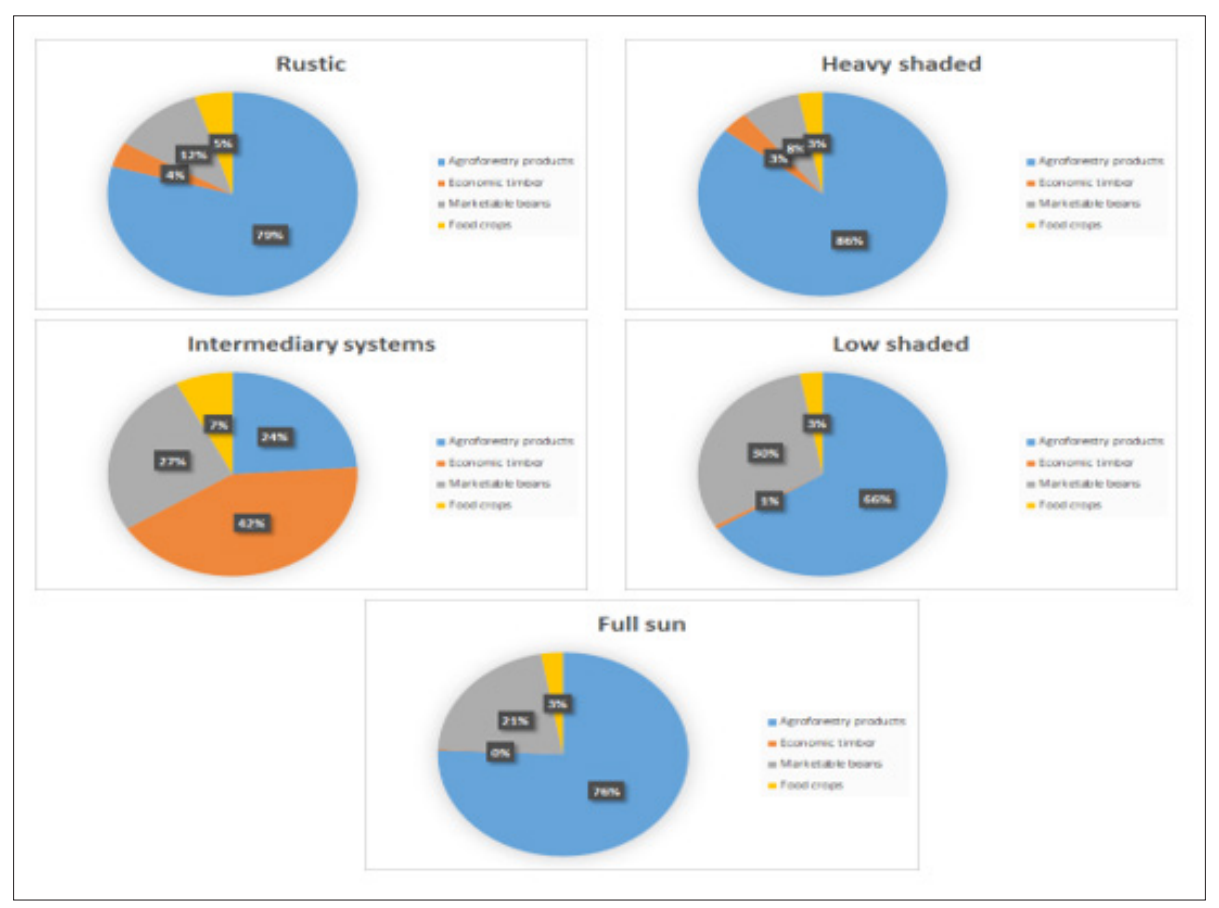

Figure 1: Revenue generated by different type of cocoa agroforestry system in US\$/ha/year. 
Although, the ongoing policy in Cameroon is recommending shade removal, it is important to have a detailed assessment of the long-term effects of shade removal on cocoa yield. This could help anticipate and mitigate any climate effects as cocoa grown in agroforestry systems might be better able to cope with the changing environment [6]. But today, establishing such biodiversity friendly farming practices such a cocoa agroforestry system will require public and private actors providing economic and financial solutions to enable smallholders to embrace the short-term transition to sustainable production models $[27,28]$.

A thorough understanding of the economics of smallholder cocoa production must underpin these solutions. Small plantation owners in particular need funding to offset losses incurred in the early years of the transition to agroforestry. But local banks do not lend to smallholders. To address this, one solution could be longterm purchase contracts with the chocolate companies to smooth out small planter's cocoa incomes and provide them with a steady income. Over the next ten years, it will be crucial for Côte d'Ivoire to implement its zero-deforestation agricultural policy to achieve its international climate commitments, ensure the sustainability of cocoa production and lift farmers out of poverty. This will mean converting an estimated two million hectares of cocoa plantations to agroforestry. The EU REDD Facility and the UNEP Finance Initiative study suggests this would correspond to a financing requirement equivalent to EUR 671 million over the first three years.

Funding agroforestry and combining it with other solutions to effectively combat deforestation and sustain productivity are critical. The mix will be key to ensuring that Côte d'Ivoire's climate and zero-deforestation commitments are coherent with the sustainability strategies of actors in the cocoa sector-particularly through the Action Plan of the Cocoa and Forests Initiative-and with the harsh economic reality of small cocoa plantation owners. Côte d'Ivoire must take into account macroeconomic issues affecting the sector when considering scaling up agricultural intensification and agroforestry pilots in cocoa plantations. If Côte d'Ivoire can strike the right balance, it may be possible within a decade to buy chocolate whose production is not only deforestation-free but also allows rainforests to spread once more. Ultimately, what could taste better than chocolate that is good for the climate, for biodiversity and for the farmers who produce it? A guilt-free sweet tooth indeed!

\section{Helping cocoa farmers thrive through a new approach}

According to estimates by The McKinzey Global Institute in 2010, Africa has around 600 million hectares of uncultivated arable land. This constitutes approximately $60 \%$ of all the arable land left in the world to meet the food needs of nine billion people on the planet by the year 2050. Data from Africa-wide surveys of land degradation by the Montpellier Panel in 2014 reporting on conserving, restoring, and enhancing Africa's soil show that about $65 \%$ of the cultivated lands in Africa are infertile due to soil erosion and high population growth resulting in poor crop yields. Recent data from the Vivid Economics and World Resources Institute's Global Forest Watch in 2019 showed that the conversion of tropical forests into fields supporting commodity production has led to one of the highest deforestation rates in Africa, with up to $3.2 \%$ of forest remnants converted to agricultural lands per year. Cocoa agribusiness and cocoa expansion are reported to drive deforestation in West Africa. This high deforestation rate puts tropical biodiversity in danger and may negatively impact socio-economic conditions, environmental conditions, ecosystems services, and the livelihoods of several million farmers. Without significant investments into the restoration of productivity, these lands will be unviable for cocoa and food production. The consequences of deforestation, land degradation, and poor farming practices are that the continent cannot grow enough food to feed the growing demand and increasingly urbanized population. In West Africa, agriculture is the largest employer of people, as most of the food produced comes from the farms and fields of smallholders. However, the continent suffers food shortages, mainly arising from low production, lack of proper storage, a weak supply chain, and economic systems. This is especially the case in the face of climate change, deforestation, and land degradation that threatens agriculture and the regulation and provision of critical ecosystem services. In recognition of these challenges, various projects to promote growth and youth entrepreneurship in the cocoa and agricultural sector have been initiated on the continent.

Investments in input and technology-based expansion of cocoa production echoes the "Green Revolution" approach, with radical transformation of agriculture through "revolutionary" development of improved planting materials and high-tech approaches. This approach is characterized by the loss of landscape complexity and ecological integrity, generally resulting from human activities and mono-cropping, high dependency on chemical inputs such as fertilizers and pesticides, and intensive slash and burn and forest clearing. Such approaches have resulted in massive production and productivity gains, most notably in Côte d'Ivoire, where they have been justifiably credited with averting poverty. While this strategy has succeeded to lift some people out of poverty, it remains unsustainable over the long term and requires a fundamental reconsideration of the industry's approach to cocoa production, considering ecological needs and household realities. Such agro-ecogical based consideration will save the next generation from bearing the brunt of ecological costs caused by increased deforestation and land degradation, mostly through soil compaction and loss of organic matter, as a result of intensive farming with only chemical fertilizer inputs.

Many smallholder cocoa farmers in Africa lack the minimum physical, human, and financial asset endowments to enable them to efficiently adopt this "Green Revolution" approach due to its relative complexity. Moreover, this approach might not be fully suitable for the livelihood diversification strategies of smallholder farmers who usually spread their risks through mixed cropping systems, including agroforestry and combining farm income with non-farm income such as petty trading and other income generating activities. In other words, there is a need to adapt the "Green Revolution" approach to the local ecological, social, and economic conditions. Transformative cocoa production initiatives are often promising in principle, but in implementation, strong considerations should 
be made in terms of sustainability as requested by the Sustainable Development Goals and the Paris Agreement. There is no question that investments in better inputs are necessary. It is, however, important to acknowledge that they are not enough to deliver lasting solutions for smallholder cocoa farmers and producing countries. A strategy that ignores the need for investing in 'safety nets' and sustainability will only shore up investments in inputs to deliver short-lived gains, leaving cocoa farmers exposed to climate change, degraded soils and landscapes, and changing demographics in the future. I argue that a balanced portfolio of investments in revitalizing cocoa farming should include stakes in resilient productivity. This will require going beyond mere contributions in improved inputs to seeking investments that couple productivity and production increases with the ability of such gains to withstand shocks of various kinds-economic, social, ecological, and climatic. An investment strategy that aims to deliver resilient productivity can accomplish food security goals with an appropriate emphasis on applying the precautionary principle, thus assuring the 'security' component and a class of prosperous cocoa farmers in empowered communities on a healthy planet.

\section{Resilient Productivity: What it means and why it is essential}

Resilience as a concept is increasingly forming the cornerstone for the work of governments, multilateral organizations, and financial institutions. The Africa Union Vision 2063, for instance, aims to support the resilience of livelihood systems through adapted practices to land tenure systems, poverty situations, market/ financial realities, and ecological conditions. Resilience is defined in ecology as the capacity of a system to absorb disturbance and reorganize while undergoing change as to still retain essentially the same function, structure, identity, and feedbacks (Walter et al, 2004 in Ecology \& Society). On the other hand, macroeconomic resilience has two components: Instantaneous resilience-the ability to limit the magnitude of immediate production losses for a given amount of asset losses-and dynamic resilience-the ability to reconstruct and recover.

In my use of the term resilient productivity, I draw on broadly accepted definitions of resilience and apply them to an interest in cocoa productivity increases in Africa. This means promoting the maximum level of agricultural productivity at which a cocoa production landscape can withstand or absorb disturbance or shocks while also delivering other ecosystem functions important to human beings. This applies to the agroecological components of the system as much as it does to the agroeconomic and livelihood components. The strategy including prosperous farmers, empowered communities, and a healthy plant, for example, would result in changes in production systems while considering the natural capital that exists as the matrix within which cocoa production takes place on farmers' fields, and in farmer communities and landscapes. It acknowledges that such agricultural landscapes have functions beyond the production of cocoa-the diversity of value chains in a given territory, capacity of the marketing systems to change in response to the changing business and political-legal environment; as well as the delivery of water, management of disease, especially transboundary diseases, the delivery of energy, fiber, and building materials and of otherwise safe and healthy environments are also important.

Finally, these landscapes must be able to withstand disturbances and shocks. By turning attention from modernized agriculture and investments to agro-chemical and allied industries, initiatives aimed at boosting production ignore nature and instead focus on market-based finance and business investments. Cocoa and agricultural promotion initiatives need to team up with agronomists, agro-ecologists, social-ecologists, and the engineering world to achieve a sector transformation that uses evidencebased, smart solutions. Great cities emerge from a combination of planning and self-organization. In a similar way, prosperous farmers in empowered communities on a healthy planet will need a combination of targeted technologies such as zero-carbon energy, climate-smart technologies, and resilient practices; forward-looking infrastructure plans at the local, national, and regional levels; and the usual surprises, breakthroughs, and evolution of market-based change including an enabling environment of favorable policies and regulations.

\section{What are the available options?}

Strategies to effectively link productivity and resilience tend to be disconnected and, in many cases, work against each other. Given the trend towards sustainable development and the need to minimize ecological footprints of economic activities, linking productivity and resilience should be the basis for an alternative approach to targeting agricultural investments with more realistic, long-term expectations that meet societal demands sustainably-that is, no significant erosion of ecological functioning and preservation of natural capital.

Building resilience into productivity and production gains will require paying simultaneous attention to the following seven overarching issues:

1) Closing yield gaps through sustainable intensification technologies such as agroforestry systems that combine production and preservation of ecosystems' essential functions.

2) Identifying appropriate agro-ecological practices/ strategies, constraints, and policies in favor of biodiversity conservation trade-offs or synergies and support ecosystem services.

3) Paying attention to water conservation, especially water use and re-utilization efficiency, and management of rainwater through appropriate practices and policies at scale.

4) Introducing policy reforms that restructure institutional arrangements that favor youth entrepreneurship, job creation including for women, strong investment in multi-stakeholder processes, and market-based change through improvements in institutions, tenure, and governance.

5) Introducing safety and child labour policies in agricultural practices as well as facilitating access to basic socio-economic infrastructures to farming communities. 
6) Building on local knowledge, culture, and traditions while seeking innovations.

7) Investing in strengthening infrastructure for storage, transformation, and local market niche, development of postharvest technologies, enhancing efficient logistics systems, as well as provision of the right institutional and policy environment to support production and distribution.

The linkage to knowledge for transforming cocoa farming systems entails building the capacity of cocoa system actors such as individual farmers and cocoa-based households and communities to be able to adapt to, respond to, and recover from environmental, economic, and social shocks that can affect their livelihoods. We therefore need a wide degree of flexibility in approaches (Figure 2). No one formula is right for every farmer and every situation. It is vital to build resilient cocoa systems that meet the farmers where they are as individuals, taking into account their households, farm realities, and farming style.

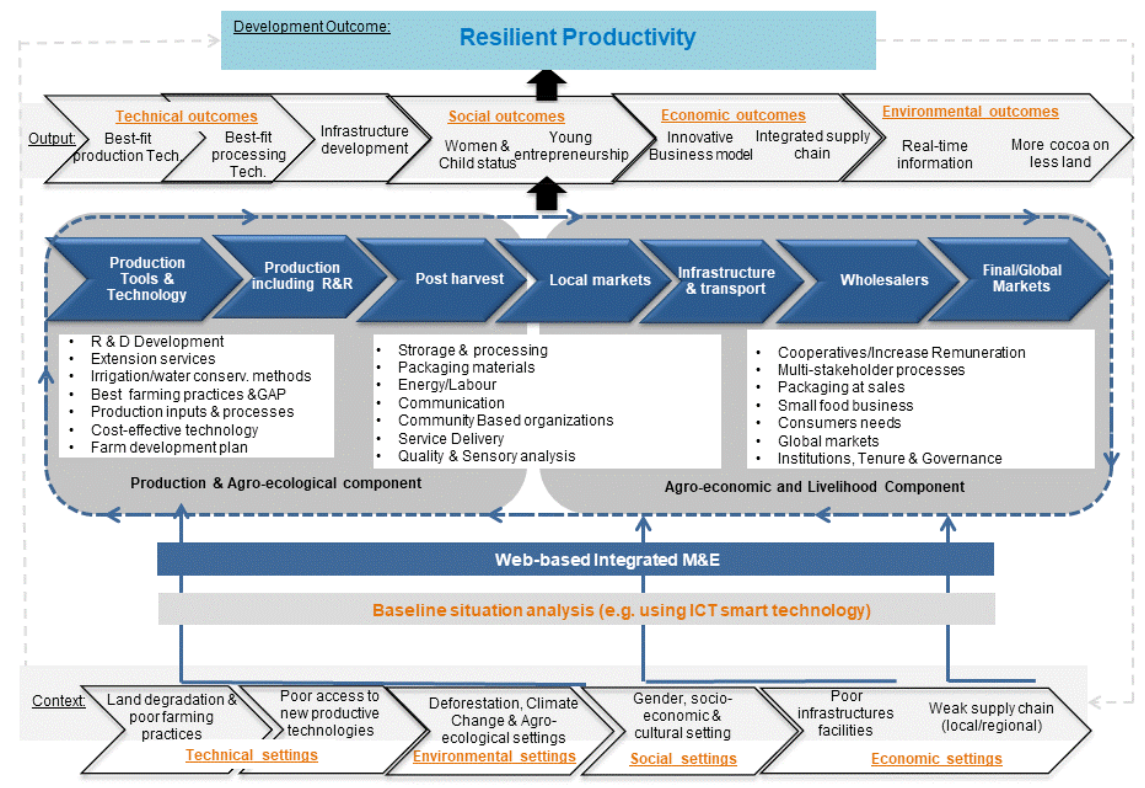

Figure 2: Conceptual framework for resilient productivity.

\section{Conclusion}

The challenge of having prosperous farmers in empowered communities on a healthy planet in West Africa lays within systems that are highly resilient, while supporting the increasing yields needed to feed a growing demand. What is needed is a genuine working model of responsible production without compromising the future. One such model is the portfolio approach that covers agroforestry and ago-ecological intensification, diversity of species, lifeforms, livelihoods, value chains, and systems. Initiatives to promote cocoa production can identify what works for various ecologies, farmers, and local communities; what seems to work over the short run and reduces risks for the long term; and what the implications are for overall food production, livelihoods, resilience, and development. This requires a new framing with a shift in narrative and practice of agriculture as part of a "bioeconomic system" for present and future needs. I now leave you with a question: Does a simplification of cocoa landscapes to a low number of species allow us to unlock the potential for future cocoa and food production needed for a healthy population, both in terms of quantity and quality?

\section{Acknowledgement}

This study is part of the fellowship project (VW-60420894) of the author funded by the Volkswagen Foundation. The author is very grateful to the Volkswagen foundation for the financial assistance.

\section{References}

1. Rice RA, Greenberg R (2000) Cacao cultivation and the conservation of biological diversity. AMBIO: A Journal of the Human Environment 29(3): 167-173.

2. Bisseleua DHB, Missoup AD, Vidal S (2009) Biodiversity conservation, ecosystem functioning, and economic incentives under cocoa agroforestry intensification. Conserv Biol 23(5): 1176-1184.

3. Dumont SE, Gnahoua GM, Ohouo L, Sinclair FL, Vaast P (2014) Farmers in Côte d'Ivoire value integrating tree diversity in cocoa for the provision of ecosystem services. Agroforestry Systems (2014) 88(6): 1047-1066.

4. Asare A, Raebild A (2016) Tree diversity and canopy cover in cocoa systems in Ghana. New Forests 47(2): 287-302.

5. Djuideu TCL, Bisseleua DH, Kekeunou S, Meupia MJ, Difouo FG, et al. (2019) Plant community composition and functional characteristics define invasion and infestation of termites in cocoa agroforestry systems. Agroforestry Systems pp. 1-17.

6. Läderach P, Martinez Valle A, Schroth G, Castro N (2013) Predicting the future climatic suitability for cocoa farming of the world's leading producer countries, Ghana and Côte d'Ivoire. Climatic Change 119(3-4): 841-854.

7. Bisseleua HBD, D Fotio, AD Missoup, Vidal S (2013) Shade tree diversity, cocoa pest damage, yield compensating inputs and farmers' net returns in West Africa. PloS One 8(3): e56115. 
8. Asare A, Ofori Frimpong K, Ekpe PK (2010) Impact of cocoa farming on vegetation in an agricultural landscape in Ghana. African Journal of Ecology 48(2): 338-346.

9. Tondoh JE, FN Kouamé, Guéi AM, Sey B, Koné AW, et al. (2015) Ecological changes induced by full-sun cocoa farming in Côte d'Ivoire. Global Ecology and Conservation 3: 575-595.

10. Tscharntke T, Clough Y, Bhagwat SA, Buchori D, Faust H, Hertel D, et al. (2011) Multifunctional shade-tree management in tropical agroforestry landscapes-a review. Journal of Applied Ecology 48(3): 619-629.

11. Ambele CF, Bisseleua DHB, Ekesi S, Komivi SA, Christian Djuideu TCL, et al. (2018b) Consequences of shade management on the taxonomic patterns and functional diversity of termites (Blattodea:Termitidae) in cocoa agroforestry systems. Ecol Evol 8(23): 11582-11595.

12. Bisseleua DHB, Idrissou L, Ogunniyi A, Atta Krah, K (2018) Diversification and livelihood strategies in the cocoa belt of West Africa: The need for fundamental change. World Development Perspectives 10(12): 73-79.

13. Asare R, Bo Markussen, Rebecca AA, Gilbert A, Anders R (2019) On-farm cocoa yields increase with canopy cover of shade trees in two agroecological zones in Ghana, Climate and Development, 11(5): 435-445.

14. Riedel J, Kägi N, Armengot L, Schneider M (2019) Effects of rehabilitation pruning and agroforestry on cacao tree development and yield in an older full-sun plantation. Experimental Agriculture 1-17.

15. Jezeer R, Verweij Pita A, Santos Maria J, Boot René GA, et al. (2017) Shaded coffee and cocoa-double dividend for biodiversity and smallscale farmers. Ecological Economics 140: 136-145.

16. Vanhove W, Vanhoudt N, Van Damme P (2016) Effect of shade tree planting and soil management on rehabilitation success of a 22-year-old degraded cocoa (Theobroma cacao L.) plantation. Agric Ecosyst Environ 219: $14-25$.

17. Tscharntke T, Tylianakis JM, Rand TA, Didham RK, Fahrig L, et al (2012) Landscape moderation of biodiversity patterns and processes-eight hypotheses. Biol Rev Camb Philos Soc 87(3): 661-685.

18. Obiri BD, Bright GA, McDonald MA, Anglaaere LCN, Cobbina J (2007) Financial analysis of shaded cocoa in Ghana. Agroforestry Systems 71(2): 139-149.
19. Gyau A, Smoot K, Kouame C, Diby L, Kahia J, et al. (2014) Farmer attitudes and intentions towards trees in cocoa (Theobroma cacao L.) farms in Côte d'Ivoire. Agroforestry Systems 88: 1035-1045.

20. Ambele FC, Bisseleua Daghela HB, Babalola 00, Ekesi S (2018a) Soildwelling insect pests of tree crops in Sub-Saharan Africa, problems and management strategies-A review. J Appl Entomol 142(6): 539-552.

21. Bitty EA, Bi SG, Bene JCK, Kouassi PK, McGraw WS (2015) Cocoa farming and primate extirpation inside Cote d'Ivoire's protected areas. Trop Conserv Sci 8(1): 95-113.

22. Sonwa DJ, Weise S, Adesina A, Nkongmeneck AB, Tchatat M, et al. (2005) Production constraints on cocoa agroforestry systems in West and Central Africa: The need for integrated pest management and multiinstitutional approaches. The Forestry Chronicle 81(3): 345-349.

23. Bobo KS, Waltert M, Sainge NM, Njokagbor J, Fermon $H$, et al. et al (2006) From forest to farmland: species richness patterns of trees and understorey plants along a gradient of forest conversion in Southwestern Cameroon. Biodivers Conserv 15(13): 4097-4117.

24. Bisseleua DHB, Begoude D, Tonnang H, Vidal S (2017) Ant-mediated ecosystem services and disservices on marketable yield in cocoa agroforestry systems 247: 407-417.

25. Jagoret P, Snoeck D, Bouambi E, Ngnogue HT, Nyassé S, et al. (2016) Rehabilitation practices that shape cocoa agroforestry systems in Central Cameroon: key management strategies for long-term exploitation. Agroforestry Systems 92(5): 1185-1199.

26. Kroeger A, Koenig S, Thomson A, Streck C (2017) Forest-and climatesmart cocoa in côte d'ivoire and Ghana: aligning stakeholders to support smallholders in deforestation-free cocoa. World Bank.

27. Asare R, Asare RA, Asante WA, Markussen BO (2017) Influences of shading and fertilization on on-farm yields of cocoa in Ghana. Exp Agric 53(3): 416-431.

28. Richard A, Ræbild A (2016) Tree diversity and canopy cover in cocoa systems in Ghana New Forests 47(2): 287-302. 